\title{
Thu nhận acid phenyllactic từ chủng vi khuẩn Lactobacillus sp. và thử nghiệm ứng dụng trong bảo quản nông sản
}

\author{
Vũ Kim Dung ${ }^{*}$ Nguyễn Như Ngọc, Lê Sỹ Dũng, Vũ Thị Ngọc Hiền \\ Truờng Đại học Lâm nghiệp, Hà Nội, Việt Nam
}

(Ngày đến tòa soạn: 03/11/2020; Ngày chấp nhận đăng: 28/01/2021)

\section{Tóm tắt}

Acid phenyllactic (PLA) là một hợp chất sinh học được sinh tổng hợp từ vi sinh vật, có khả năng ức chế sinh trưởng và sự phát triển của một số loài vi khuẩn gram âm, gram dương, cùng nhiều loài nấm men, nấm mốc gây hại thực phẩm. Kết quả nghiên cứu đã phân lập và tuyển chọn được chủng Lactobacillus sp. MX3.2 có khả năng sinh tổng hợp acid phenyllactic cao $(1,98 \mathrm{~g} / \mathrm{L})$ từ các sản phẩm rau củ muối chua. Chế phẩm PLA thu nhận từ quá trình lên men chủng Lactobacillus sp. MX3.2 có khả năng ức chế sự phát triển của nấm mốc Aspergillus niger, Aspergillus flavus và Aspergillus oryzae ở nông độ $40-50 \mathrm{~g} / \mathrm{L}$ và vi khuẩn Escherichia coli, Salmonella enterica và Shigela flexneri ở nồng độ 20 - $30 \mathrm{~g} / \mathrm{L}$. Bước đâuu thử nghiệm ứng dụng PLA trong bảo quản nông sản - thực phẩm đạt hiệu quả cao. Quả xoài và ớt khi xử lý bằng PLA $2 \%$ kết hợp với $\mathrm{CaCl}_{2} 1 \%$ trong 2 phút sau 28 ngày bảo quản vẫn giữ được độ tươi, ngon và chất lượng cảm quan tốt, kéo dài hơn so với không xử lý 14 ngày.

Tù khóa: Acid phenyllactic, bảo quản, Lactobacillus, tuyên chọn.

\section{1. ĐĂT VẤN ĐÊE}

Việt Nam là một nước có rất nhiều loại rau quả nhiệt đới với nhiều giống cây ăn quả đặc sản phù hợp cho xuất khẩu sang các thị trường ở khu vực khí hậu hàn đới. Tuy nhiên, trong những năm gần đây xuất khẩu rau quả chỉ chiếm tỷ trọng 2,5\% trong tổng giá trị xuất khẩu hàng hóa và chiếm $2 \%$ tổng GDP [1]. Một trong những nguyên nhân chính là do khâu thu hoạch, vận chuyển và bảo quản kém dẫn đến rau quả sụt giảm về mặt chất lượng rất lớn. Do đó, các nghiên cứu về việc sản xuất các chất bảo quản an toàn sinh học cũng như giá thành rẻ được thúc đẩy mạh mẽ.

Acid phenyllactic là một hợp chất sinh học mới, có tiềm năng ứng dụng như là chất bảo quản thực phẩm, sinh tổng hợp từ nhóm vi khuẩn lactic, được các nhà khoa học trên thế giới phát hiện và tập trung nghiên cứu. Nhiêu báo cáo đã chứng minh rằng PLA là một hợp chất an toàn, có khả năng ức chế cả vi khuẩn gram âm lẫn gram dương và nấm men, nấm mốc, đặc biệt là nhiều loài nấm sinh độc tố [2-4]. Với những lợi ích cũng như tiềm năng đã được kiểm chứng PLA là sản phẩm rất phù hợp sử dụng cho những đối tượng nông sản, thực phẩm dễ bị lây nhiễm bởi vi sinh vật gây hại và đòi hỏi có tính an toàn cao khi sử dụng.

Trên quy mô lớn, PLA có thể được thu hồi từ dịch lên men chứa nhiều tạp chất bằng phương pháp hóa học [5]. PLA trong dịch lên men phản ứng với $\mathrm{Ca}(\mathrm{OH})_{2}$ tạo kết tủa muối canxi phenyllactat, dùng kết tủa này phản ứng với $\mathrm{H}_{2} \mathrm{SO}_{4}$ sẽ tạo ra sản phẩm là PLA dạng dung dịch và kết tủa $\mathrm{CaSO}_{4}$, sau đó lọc hoặc ly tâm để thu dung dịch PLA. 
Hiện nay, những công trình nghiên cứu và ứng dụng PLA trên thế giới và ở Việt Nam mới dừng ở phạm vi tuyển chọn những chủng vi khuẩn lactic có khả năng sinh PLA cao để bổ sung vào thức ăn chăn nuôi, chỉ có một vài nghiên cứu thử nghiệm sản xuất PLA thông qua quá trình lên men ở quy mô nhỏ và thử nghiệm bảo quản rau quả chế biến tối thiểu $[2,5]$. Do đó nghiên cứu phân lập và tuyển chọn được chủng Lactobacillus sp. có khả năng sinh tổng hợp acid phenyllactic cao ứng dụng trong bảo quản nông sản - thực phẩm rất có ý nghĩa.

Acid phenyllactic được sinh tổng hợp từ nhiều loại vi sinh vật [10], tuy nhiên các loài vi khuẩn Lactobacillus như: L. plantarum, L. acidophilus, L. paracasei có khả năng sinh PLA cao hơn [11]. Do vậy, để tuyển chọn được chủng vi sinh vật có khả năng sinh PLA cao, cần tập trung phân lập các chủng vi khuẩn Lactobacillus sp.

\section{VẬT LIỆU VÀ PHƯƠNG PHÁP}

\subsection{Vật liệu nghiên cứu}

Rau củ muối thu thập từ chợ Xuân Mai và Hà Đông tại Hà Nội

Chủng đối chứng: Shigela flexneri S1, Samonela enterica ST, Escherichia coli T1, Staphylococcus aureus SA, Apergillus niger LN02, Apergillus oryzae A4, Apergillus flavus do bộ sưu tập giống của Bộ môn Công nghệ vi sinh - Hóa sinh, Viện Công nghệ sinh học Lâm nghiệp cung cấp.

Hóa chất: môi trường nuôi cấy vi sinh vật từ hãng HiMedia và một số hóa chất khác từ Trung Quốc.

Thiết bị: sử dụng các thiết bị thường quy trong nghiên cứu vi sinh vật, bao gồm: kính hiển vi (Olympus - Nhật Bản), tủ sấy (Memmert - Đức), tủ nuôi (GYROMAX 737- Mỹ), thiết bị khử trùng (Hirayama - Nhật Bản), tủ cấy vi sinh (CHCLab - Hàn Quốc).

\subsection{Phương pháp nghiên cứu}

\subsubsection{Phân lập và định danh các chủng vi khuân Lactobacillus sp.}

Các chủng Lactobacillus sp. được phân lập theo phương pháp của Nguyễn Thị Minh Hằng và cộng sự, từ mẫu rau củ muối chua được thu thập từ chợ ở Xuân Mai và Hà Đông - Hà Nội, dựa trên đặc điểm hình thái của khuẩn lạc, hình thái vi khuẩn, tính chất gram, hoạt tính catalase, khả năng di động, khả năng sinh acid lactic [6].

Sàng lọc chủng có khả năng sinh acid lactic cao: Vi khuẩn được nuôi trong môi trường MRS lỏng (Lactobacillus MRS Broth) trong 48 giờ ở $37^{\circ} \mathrm{C}$, tốc độ lắc 200 vòng/phút. Xác định hàm lượng acid tạo ra bằng phương pháp chuẩn độ Therner [6], từ đó lựa chọn các chủng sinh acid lactic cao.

Tuyển chọn chủng sinh PLA cao: quá trình tuyển chọn dựa trên nguyên lý PLA phản ứng đặc hiệu với $\mathrm{Ca}(\mathrm{OH})_{2}$ tạo canxi phenyllactat kết tủa nên chủng vi sinh vật tạo ra lượng lớn PLA sẽ tạo nhiều kết tủa canxi phenyllactat khi đưa $\mathrm{Ca}(\mathrm{OH})_{2}$ vào dịch nuôi cấy. Sau đó tiếp tục sàng lọc các chủng này dựa trên kết quả xác định hàm lượng PLA tạo thành bằng HPLC [10] để lựa chọn chủng có khả năng sinh PLA cao nhất.

Định tên chủng vi khuân tuyển chọn: Sử dụng Kit API 50 CHL Medium (API system, France) với 49 loại đường để định tên chủng theo phương pháp của Aras và cộng sự [7]. 


\subsubsection{Thu PLA tù canh trường vi khuân}

Các chủng có khả năng sinh PLA cao được nuôi trong môi trường MRS lỏng với tốc độ 100 vòng/phút trong 72 giờ ở nhiệt độ $37^{\circ} \mathrm{C}$. Ly tâm thu dịch canh trường, bổ sung $\mathrm{Ca}(\mathrm{OH})_{2} 10 \%$ tới $\mathrm{pH}=10$ và kết tinh muối ở $5^{\circ} \mathrm{C}$ trong 18 giờ. Lọc thu muối kết tủa (Canxiphenyllactat), sấy ở $50^{\circ} \mathrm{C}$ trong 12 giờ và cân lượng muối thu được. Bổ sung acid $\mathrm{H}_{2} \mathrm{SO}_{4} 98 \%$ với lượng vừa đủ để tạo kết tủa $\mathrm{CaSO}_{4}$. Rửa mẫu 03 lần bằng nước cất vô trùng và ly tâm ở 1.500 vòng/phút ở $4^{\circ} \mathrm{C}$ bằng thiết bị li tâm, lọc thu dịch PLA [5].

\subsubsection{Xác định hoạt tính kháng khuân và nấm của PLA}

Khả năng kháng vi sinh vật của chế phẩm PLA: được xác định theo phương pháp khuếch tán thạch (agar diffusion) [8]. Môi trường thạch có chứa $10^{5} \mathrm{CFU} / \mathrm{mL}$ chủng cần kiểm tra đã được nuôi cấy. Giếng thạch được đục trên môi trường có đường kính $7 \mathrm{~mm}(\mathrm{~d})$ và $150 \mu \mathrm{L}$ chế phẩm PLA được cho vào trong giếng. Giữ nguyên đĩa thạch ở điều kiện $4^{\circ} \mathrm{C}$ trong thời gian 05 giờ để dịch khuếch tán đều trong đĩa thạch. Nuôi cấy ở điều kiện thích hợp với từng chủng vi sinh vật và sau 02 ngày đo vòng ức chế trên đĩa thạch $(\mathrm{D}, \mathrm{mm})$. Thí nghiệm đối chứng sử dụng nước cất, mỗi công thức bố trí lặp lại 03 lần. Hoạt tính kháng khuẩn hay kháng nấm của PLA được tính bằng đường kính vòng kháng khuẩn $\Delta \mathrm{D}=\mathrm{D}-\mathrm{d}(\mathrm{mm})$.

Nồng độ ức chế tối thiểu (MIC) của chế phẩm PLA: Tiến hành pha loãng hàng loạt nồng độ PLA: 5, 10, 15, 20, 25, 30, 35, 40, 45, 50, 55, $60 \mathrm{mg} / \mathrm{mL}$ trong các bình tam giác chứa môi trường lỏng (150 mL). Bổ sung $2 \mathrm{~mL}$ dịch nuôi cấy chủng vi khuẩn (Shigela flexneri, Samonella enterica, E. coli, S. aureus) hoặc dịch bào tử nấm $\left(A\right.$. niger, A. oryzae, A. flavus) với mật độ $10^{5} \mathrm{CFU}$ (bào tử) $/ \mathrm{mL}$ vào môi trường và nuôi trong 24 giờ ở $37^{\circ} \mathrm{C}$ (hoặc $30^{\circ} \mathrm{C}$ với nấm mốc) với tốc độ lắc 150 vòng/phút. Cấy tráng $100 \mu \mathrm{L}$ dịch trên đĩa thạch chứa Triton X100 (mỗi nồng độ trải 3 đĩa) và nuôi trong 48 giờ ở $37^{\circ} \mathrm{C}$ (hoặc $30^{\circ} \mathrm{C}$ với nấm). Xác định mật độ của khuẩn lạc vi khuẩn trên các đĩa thạch ở mỗi nông độ PLA. Công thức đối chứng (không bổ sung chế phẩm PLA) được thực hiện giống như ở công thức thí nghiệm.

Nồng độ MIC được tính ở nồng độ PLA thấp nhất có thể ức chế được sự phát triển của vi khuẩn và nấm mốc [9].

\subsection{4. Úng dung của PLA trong bảo quản xoài và ớt}

Xoài và ớt tươi sau khi lựa chọn, rửa bằng dung dịch natri hypocloride 200 ppm và tráng lại bằng nước cất. Cân $300 \mathrm{~g}$ ớt và $1 \mathrm{~kg}$ xoài nhúng vào $500 \mathrm{~mL}$ dung dịch đã chuẩn bị sẵn gồm PLA ở các nồng độ khác nhau, $1 \% \mathrm{CaCl}_{2}$. Sau 2 phút, mẫu được lấy ra, để ráo trong 5 phút rồi xếp vào khay xốp và được bao kín lại bằng màng $\mathrm{PVC}$ và theo dõi trong 28 ngày ở $4^{\circ} \mathrm{C}-5^{\circ} \mathrm{C}[5]$. Đánh giá hiệu quả của bảo quản bằng PLA thông qua các chỉ tiêu cảm quan của sản phẩm.

\subsubsection{Phương pháp đánh giá cảm quan}

Đánh giá tổng quát mức chất lượng của sản phẩm so với tiêu chuẩn hoặc so với các sản phẩm cùng loại trên tất cả các chỉ tiêu cảm quan: màu sắc, mùi, vị và trạng thái. Hội đông đánh giá cảm quan gồm 30 thành viên được huấn luyện đây đủ về nhận biết các mùi, vị cơ bản; mô tả các đặc tính của sản phẩm đến đánh giá cho điểm (theo TCVN 11186:2015 và TCVN 12387:2018). Trong quá trình đánh giá các thành viên được cung cấp nước lọc để súc miệng sau khi đánh giá từng mẫu thử. Tiến hành đánh giá chất lượng cảm quan của sản phẩm bằng phép thử cho điểm thị hiếu (Bảng 1) theo thang điểm Hedonic từ 1 điểm (hoàn toàn không thể chấp nhận) đến 9 điểm (tuyệt vời). 
Bảng 1. Mô tả đặc điểm của quả xoài theo thang điểm cảm quan

\begin{tabular}{|c|c|c|c|c|c|c|}
\hline \multirow{3}{*}{$\begin{array}{c}\text { Điêm } \\
\text { cảm } \\
\text { quan }\end{array}$} & \multicolumn{6}{|c|}{ Chỉ tiêu đánh giá } \\
\hline & \multicolumn{2}{|c|}{ Màu sắc } & \multicolumn{2}{|c|}{$M u ̀ i, v i ̣$} & \multicolumn{2}{|c|}{ Trạng thái } \\
\hline & Xoài & $\hat{O C t}$ & Xoài & $\widehat{O ̈ t}$ & Xoài & $\hat{O H t}$ \\
\hline 9 & $\begin{array}{l}\text { Màu vàng sáng } \\
\text { tự nhiên }\end{array}$ & $\begin{array}{l}\text { Màu tươi } \\
\text { sáng tự nhiên }\end{array}$ & $\begin{array}{l}\text { Mùi thơm đặc } \\
\text { trủng, vị ngọt }\end{array}$ & $\begin{array}{l}\text { Mùi đặc } \\
\text { trưng, vị cay }\end{array}$ & $\begin{array}{l}\text { Thịt quả chắc, vỏ } \\
\text { tươi, bể mặt bóng }\end{array}$ & $\begin{array}{c}\text { Cứng chắc, } \\
\text { tươi, bề mặt } \\
\text { bóng }\end{array}$ \\
\hline 8 & Màu vàng tươi & Màu đỏ tươi & $\begin{array}{l}\text { Mùi thơm, vị } \\
\text { ngọt }\end{array}$ & $\begin{array}{l}\text { Mùi thơm, } \\
\text { vị cay }\end{array}$ & $\begin{array}{l}\text { Thịt quả chắc, } \\
\text { tươi, bể mặt bóng }\end{array}$ & $\begin{array}{l}\text { Cứng chắc, } \\
\text { tươi, } \\
\text { bề mặt bóng }\end{array}$ \\
\hline 7 & Màu vàng & Màu đỏ & $\begin{array}{l}\text { Mùi thơm, vị } \\
\text { ngọt nhẹ }\end{array}$ & $\begin{array}{l}\text { Mùi thơm, } \\
\text { vị cay ít }\end{array}$ & $\begin{array}{l}\text { Thit quả không } \\
\text { chắc, bể mặt ướt }\end{array}$ & $\begin{array}{l}\text { Cứng, bề } \\
\text { mặt khô }\end{array}$ \\
\hline 6 & Màu vàng đậm & Màu đỏ đậm & $\begin{array}{l}\text { Mùi thơm } \\
\text { nhẹ, vị ngọt } \\
\text { nhẹ }\end{array}$ & $\begin{array}{l}\text { Mùi thơm } \\
\text { nhẹ, vị cay ít }\end{array}$ & $\begin{array}{l}\text { Thịt quả mềm, bề } \\
\text { mặt ướt }\end{array}$ & $\begin{array}{l}\text { Cứng, chắc, } \\
\text { bể mặt khô } \\
\text { và thô }\end{array}$ \\
\hline 5 & Màu vàng sẫm & Màu đỏ sẫm & $\begin{array}{l}\text { Mùi thơm } \\
\text { nhẹ, vị chua }\end{array}$ & $\begin{array}{l}\text { Mùi thơm } \\
\text { nhẹ, vị lạ }\end{array}$ & $\begin{array}{l}\text { Thịt quả mềm, bề } \\
\text { mặt nhớt }\end{array}$ & $\begin{array}{c}\text { Thịt quả } \\
\text { mềm, bề mặt } \\
\text { nhớt }\end{array}$ \\
\hline 4 & Màu vàng sẫm & Màu đỏ sẫm & $\begin{array}{l}\text { Mất mùi } \\
\text { thơm, vị lạ }\end{array}$ & $\begin{array}{l}\text { Mất mùi } \\
\text { thơm, vị lạ }\end{array}$ & $\begin{array}{c}\text { Thịt quả mềm } \\
\text { nhiêu, bề mặt } \\
\text { nhớt }\end{array}$ & $\begin{array}{l}\text { Thịt quả } \\
\text { mềm nhiêu, } \\
\text { bế mặt nhớt }\end{array}$ \\
\hline 3 & $\begin{array}{c}\text { Màu vàng sẫm, } \\
\text { xuất hiện một } \\
\text { số đốm đen }\end{array}$ & $\begin{array}{c}\text { Màu đỏ sẫm, } \\
\text { xuất hiện một } \\
\text { số đốm lạ }\end{array}$ & Mùi lạ, vị lạ & Mùi lạ, vị lạ & $\begin{array}{c}\text { Thịt quả nhũn, } \\
\text { tiết nhiều dịch } \\
\text { quả }\end{array}$ & Mềm nhũn \\
\hline 2 & $\begin{array}{c}\text { Màu vàng sẫm, } \\
\text { xuất hiện nhiêu } \\
\text { đốm đen }\end{array}$ & $\begin{array}{l}\text { Màu đỏ sẫm, } \\
\text { xuất hiện } \\
\text { nhiêu đốm lạ }\end{array}$ & Mùi lạ & Mùi lạ & $\begin{array}{l}\text { Thịt quả nhũn } \\
\text { nát, tiết nhiểu } \\
\text { dịch quả }\end{array}$ & $\begin{array}{l}\text { Mềm nhũn } \\
\text { nát }\end{array}$ \\
\hline 1 & $\begin{array}{l}\text { Phần quả thâm } \\
\text { đen lớn }\end{array}$ & $\begin{array}{l}\text { Diện tích } \\
\text { đốm lớn }\end{array}$ & Mùi lạ nhiêu & Mùi lạ & $\begin{array}{l}\text { Thịt quả nhũn } \\
\text { nát, tiết nhiểu } \\
\text { dịch quả }\end{array}$ & $\begin{array}{l}\text { Mềm nhũn } \\
\text { nát }\end{array}$ \\
\hline
\end{tabular}

\subsection{6. Đánh giá và xủ lý số liệu}

Các thí nghiệm được lặp lại 03 lần và các kết quả nghiên cứu là trung bình của 03 lần lặp lại, số liệu được xử lý bằng phần mềm Excel.

\section{KẾT QUẢ VÀ THẢO LUẬN}

\subsection{Phân lập và tuyển chọn chủng vi khuẩn Lactobacillus sp.}

\subsubsection{Phân lập chủng Lactobacillus sp.}

Kết quả thu được thể hiện ở Bảng 2 cho thấy từ 43 mẫu rau củ muối chua đã phân lập được 31 chủng vi khuẩn có hình thái khuẩn lạc tròn, nhẵn, màu trắng sũa, gram dương, hình que, hoạt tính catalase âm tính, không có khả năng di động; có vòng phân giải $\mathrm{CaCO}_{3}$ với $\mathrm{D}$ - $\mathrm{d}$ từ 9 - 11 mm (Hình 1). 
Bảng 2. Kết quả phân lập chủng vi khuân Lactobacillus sp.

\begin{tabular}{cccc}
\hline TT & Mẫu phân lập & Số mẫu phân lập & $\begin{array}{c}\text { Số chủng Lactobacillus sp. } \\
\text { phân lập được }\end{array}$ \\
\hline 1 & Măng chua & 8 & 11 \\
2 & Cà muối & 10 & 4 \\
3 & Rau cải muối chua & 6 & 2 \\
4 & Hành muối & 10 & 5 \\
5 & Sung muối & 9 & 9 \\
\hline Tổng số & & 43 & 31 \\
\hline
\end{tabular}

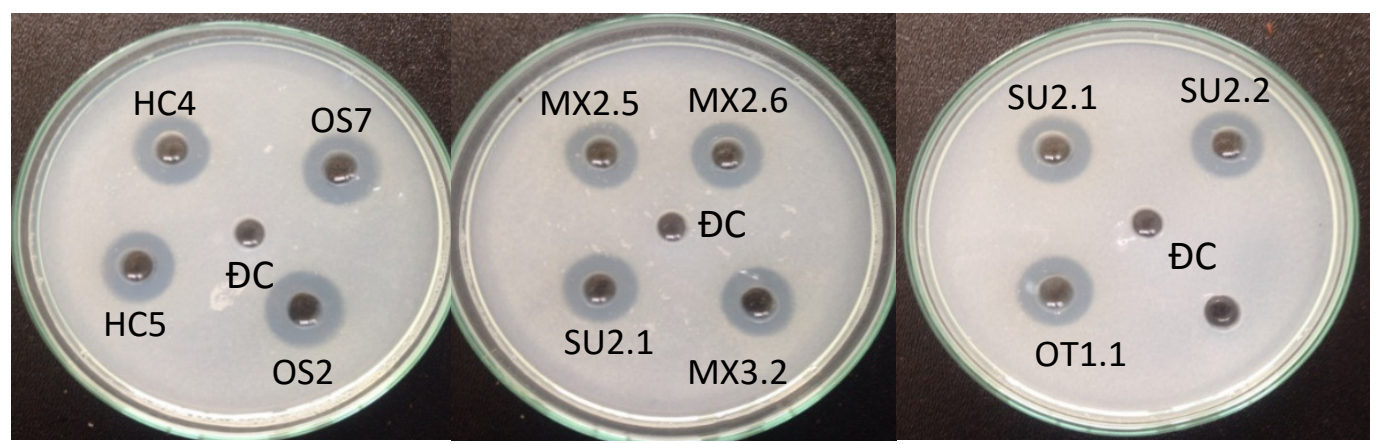

Hình 1. Khả năng phân giải $\mathrm{CaCO}_{3}$ của các chủng Lactobacillus sp.

\subsubsection{Sàng lọc các chủng vi khuân sinh acid lactic cao}

Kết quả sàng lọc được thể hiện ở Bảng 3 cho thấy khả năng sinh acid của các chủng nằm trong khoảng từ 1,26 - 1,84 g/L. Trong đó các chủng MV3.2 là chủng sinh acid yếu nhất với hàm lượng $1,26 \mathrm{~g} / \mathrm{L}$. Hai chủng MX3.2 và $\mathrm{MX} 2.5$ có khả năng sinh acid mạnh nhất với hàm lượng 1,84 g/L. Lựa chọn 10 chủng có khả năng sinh acid lactic cao $(1,71-1,84 \mathrm{~g} / \mathrm{L})$ bao gồm các chủng: HC4, HC5 (từ hành muối); MX2.5, MX2.6, MX3.2 (từ măng muối); OS2, OS7, OT1 (từ cà muối); SU2.1, SU2.2 (từ sung muối). Số lượng vi khuẩn lactic phân lập được tương đương với một số công bố của tác giả khác. Nguyễn Thị Minh Hằng và cộng sự đã phân lập từ mẫu nước dưa và cà muối được 07 chủng vi khuẩn lactic [6]. Huỳnh Ngọc Tâm và cộng sự phân lập từ dưa lê non muối chua được 19 dòng vi khuẩn lactic [12].

Bảng 3. Hàm lượng acid lactic trong dịch lên men của các chủng phân lập

\begin{tabular}{ccccccccc}
\hline TT & $\begin{array}{c}\text { Tên } \\
\text { chủng }\end{array}$ & $\begin{array}{c}\text { Hàm lương } \\
\text { acid }(\boldsymbol{g} / \mathbf{L})\end{array}$ & TT & $\begin{array}{c}\text { Tên } \\
\text { chủng }\end{array}$ & $\begin{array}{c}\text { Hàm lự̆ng } \\
\text { acid }(\boldsymbol{g} / \mathbf{L})\end{array}$ & TT & $\begin{array}{c}\text { Tên } \\
\text { chủng }\end{array}$ & $\begin{array}{c}\text { Hàm lượng } \\
\text { acid }(\boldsymbol{g} / \mathbf{L})\end{array}$ \\
\hline 1 & CA 2.3 & $1,30 \pm 0,01$ & 12 & MX 3.4 & $1,53 \pm 0,01$ & 23 & HC2 & $1,75 \pm 0,03$ \\
2 & DU 2.5 & $1,35 \pm 0,02$ & 13 & MO 1.1 & $1,57 \pm 0,01$ & 24 & HC3 & $1,35 \pm 0,01$ \\
3 & MV 1.1 & $1,39 \pm 0,01$ & 14 & OT1 & $1,71 \pm 0,02$ & 25 & HC4 & $1,80 \pm 0,02$ \\
4 & MV 2.5 & $1,48 \pm 0,01$ & 15 & SU 1.5 & $1,53 \pm 0,01$ & 26 & HC5 & $1,75 \pm 0,02$ \\
5 & MV 2.6 & $1,62 \pm 0,03$ & 16 & SU 1.6 & $1,62 \pm 0,01$ & 27 & OS2 & $1,71 \pm 0,03$
\end{tabular}




\begin{tabular}{ccccccccc}
6 & MV 3.1 & $1,57 \pm 0,02$ & 17 & SU 2.1 & $1,71 \pm 0,03$ & 28 & OS3 & $1,39 \pm 0,01$ \\
7 & MV 3.2 & $1,26 \pm 0,01$ & 18 & SU 2.2 & $1,71 \pm 0,03$ & 29 & OS5 & $1,48 \pm 0,01$ \\
8 & MV 3.4 & $1,53 \pm 0,01$ & 19 & NDH2 & $1,57 \pm 0,01$ & 30 & OS6 & $1,30 \pm 0,01$ \\
9 & MX 2.5 & $1,84 \pm 0,03$ & 20 & LT6 & $1,62 \pm 0,02$ & 31 & OS7 & $1,75 \pm 0,02$ \\
10 & MX 2.6 & $1,71 \pm 0,03$ & 21 & LT7 & $1,39 \pm 0,01$ & & Đối & \\
11 & MX 3.2 & $1,84 \pm 0,02$ & 22 & HC1 & $1,44 \pm 0,01$ & & chứng & $0,18 \pm 0,00$ \\
\hline
\end{tabular}

3.1.3. Tuyên chọn chủng sinh acid phenyllactic cao

Do PLA phản ứng hóa học đặc hiệu với $\mathrm{Ca}(\mathrm{OH})_{2}$ tạo kết tủa muối canxi phenyllactat, kết tủa này phản ứng với $\mathrm{H}_{2} \mathrm{SO}_{4}$ sẽ tạo ra sản phẩm là $\mathrm{PLA}$ dạng dung dịch và kết tủa $\mathrm{CaSO}_{4}$. Loại bỏ kết tủa sẽ thu được dung dịch PLA. Như vậy, lượng PLA trong dịch lên men càng lớn thì lượng muối canxi phenyllactat tạo ra càng nhiều. Dựa vào nguyên lý này, quá trình tuyển chọn chủng có khả năng sinh PLA cao sẽ được lựa chọn từ chủng có dịch lên men tạo lượng muối cao nhất với $\mathrm{Ca}(\mathrm{OH})_{2}$.

Trong số 10 chủng có khả năng sinh acid lactic cao, MX3.2 có khả năng tạo nhiêu muối kết tinh nhất $(4,05 \mathrm{mg} / \mathrm{L})$, các tinh thể to, rõ ràng (Hình 2), một số chủng (MX2.6, SU2.1, SU2.2, HC5, OS2, OS7) tạo ra tinh thể muối canxi phenyllactat rất ít $(0,02-0,07 \mathrm{~g} / \mathrm{L})$, tinh thể ở dạng bông, khó thu nhận; đối chứng (môi trường lên men) không tạo muối kết tinh (Bảng 4).

Bảng 4. Hàm lượng muối canxi phenyllactat kết tinh của chủng Lactobacillus sp.

\begin{tabular}{cccc}
\hline $\boldsymbol{T} T$ & Tên chủng & $\begin{array}{c}\text { Hàm luọng muối canxi } \\
\text { phenyllactat }(\mathbf{g} / \mathbf{L})\end{array}$ & Hàm lượng PLA $(\mathbf{g} / \mathbf{L})$ \\
\hline 1 & MX 2.5 & $1,10 \pm 0,04$ & $0,79 \pm 0,02$ \\
2 & MX 2.6 & $0,05 \pm 0,002$ & $0,04 \pm 0,003$ \\
3 & MX 3.2 & $4,05 \pm 0,05$ & $2,92 \pm 0,04$ \\
4 & OT1 & $1,40 \pm 0,04$ & $1,01 \pm 0,05$ \\
5 & Su 2.1 & $0,07 \pm 0,002$ & $0,05 \pm 0,002$ \\
6 & Su 2.2 & $0,02 \pm 0,001$ & $0,01 \pm 0,001$ \\
7 & HC4 & $2,15 \pm 0,05$ & $1,55 \pm 0,04$ \\
8 & HC5 & $0,05 \pm 0,003$ & $0,04 \pm 0,003$ \\
9 & OS2 & $0,06 \pm 0,002$ & $0,04 \pm 0,001$ \\
\hline 11 & OS7 & $0,04 \pm 0,001$ & $0,03 \pm 0,001$ \\
\hline
\end{tabular}



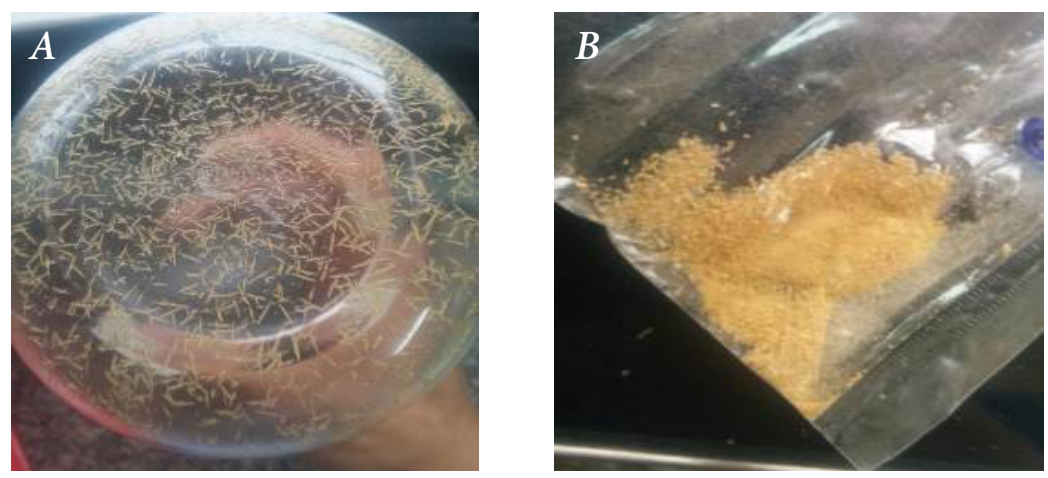

Hình 2. Tinh thể muối canxi phenyllactat A: ở dạng kết tinh, B: sau khi sấy khô

Về mặt lý thuyết, nếu toàn bộ PLA ở dịch môi trường nuôi cấy chuyển hóa hoàn toàn thành muối canxi phenyllactat và hiệu suất thu nhận canxi phenyllactat kết tinh $100 \%$ thì cứ $1,00 \mathrm{~g} / \mathrm{L}$ PLA sẽ tạo thành 1,39 $\mathrm{g} / \mathrm{L}$ canxi phenyllactat. Do đó, chủng MX3.2 có khả năng sinh tổng hợp PLA cao nhất (hàm lượng 2,92 g/L), các chủng MX2.5, HC4, OT1 tạo ra PLA lượng thấp hơn $(0,79-1,55 \mathrm{~g} / \mathrm{L})$. Bên cạnh đó, hàm lượng PLA xác định bằng HPLC của chủng MX3.2 (1,98 g/L) cao hơn chủng HC4 (1,16 g/L). Như vậy, chủng MX3.2 đã được lựa chọn cho nghiên cứu tiếp theo.

Chủng Lactobacillus sp. MX3.2 sinh tổng hợp PLA tương đối cao so với một số báo cáo của các tác giả khác. Li và cộng sự đã sử dụng chủng Lactobacillus sp. SK007 sinh tổng hợp PLA $1,13 \mathrm{~g} / \mathrm{L}$ [13]. Kamata và cộng sự sử dụng chủng Brevibacterium lactofermentum tạo ra 1,92 g/L PLA [14]. Tuy nhiên, để tăng hàm lượng PLA do chủng Lactobacillus sp. MX3.2 tạo ra cần phải tiến hành các nghiên cứu về điều kiện nuôi cấy cũng như cải tạo chủng để sản xuất PLA trên quy mô lớn hơn.

\subsection{4. Định tên chủng vi khuân tuyên chọn}

Chủng Lactobacillus sp. MX3.2 được xác định khả năng lên men các loại đường bằng kit API 50 CHL Medium, cho thấy chủng tuyển chọn có khả năng lên men nhiều loại đường như: arabinose, ribose, glucose, fructose, mannose, mannitol, sorbitol, maltose, saccharose, raffinose... nhưng không có khả năng lên men glycerol, erythritol, xylose, sorbose, lactose, glycogen, fucose, arabitol... (Bảng 5) tương đông với đặc điểm của chủng Lactobacillus plantarum. Do đó, chủng tuyển chọn có thể thuộc loài Lactobacillus plantarum. Tuy nhiên để khẳng định chính xác hơn tên loài cần phải kết hợp với các nghiên cứu về sinh học phân tử.

Bảng 5. Khả năng lên men các loại đường của Lactobacillus sp. MX2.5

\begin{tabular}{|c|c|c|c|c|c|c|c|c|c|c|c|}
\hline$T T$ & Chất thử & 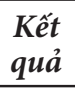 & $T T$ & Chất thư & $\begin{array}{l}\text { Kết } \\
\text { quả }\end{array}$ & $T T$ & Chất thư & $\begin{array}{l}\text { Kết } \\
\text { quả }\end{array}$ & $T T$ & Chất thư & $\begin{array}{l}\text { Kết } \\
q u a ̉\end{array}$ \\
\hline 0 & Control & - & 13 & D-Mannose & + & 26 & Salicin & + & 39 & Gentiobiose & + \\
\hline 1 & Glycerol & - & 14 & L-Sorbose & - & 27 & D-Celiobiose & + & 40 & D-Turanose & + \\
\hline 2 & Erythritol & - & 15 & L-Rhamnose & - & 28 & D-Maltose & + & 41 & D-Lyxose & - \\
\hline 3 & D-Arabinose & - & 16 & Dulcitol & - & 29 & D-Lactose & - & 42 & D-Tagatose & - \\
\hline 4 & L-Arabinose & + & 17 & Inositol & - & 30 & D-Melibiose & + & 43 & D-Fucose & - \\
\hline 5 & D-Ribose & + & 18 & D-Mannitol & + & 31 & D-Saccharose & + & 44 & L-Fucose & - \\
\hline 6 & D-Xylose & - & 19 & D-Sorbitol & + & 32 & D-Trehalose & + & 45 & D-Arabitol & - \\
\hline
\end{tabular}




\begin{tabular}{|c|c|c|c|c|c|c|c|c|c|c|c|}
\hline 7 & L-Xylose & - & 20 & $\begin{array}{c}\text { Meth- } \\
\text { yl-D-Manno- } \\
\text { pyranoside }\end{array}$ & + & 33 & Inulin & - & 46 & L-Arabitol & - \\
\hline 8 & D-Adonitol & - & 21 & $\begin{array}{c}\text { Meth- } \\
\text { yl-D-Gluco- } \\
\text { pyranoside }\end{array}$ & - & 34 & D-MeleZitose & + & 47 & $\begin{array}{l}\text { Potassium } \\
\text { Gluconate }\end{array}$ & + \\
\hline 9 & $\begin{array}{c}\text { Meth- } \\
\text { yl-D-Xy- } \\
\text { lopyraniside }\end{array}$ & - & 22 & $\begin{array}{l}\text { N-AcetylGlu- } \\
\text { cosamine }\end{array}$ & + & 35 & D-Raffinose & + & 48 & $\begin{array}{l}\text { Potassium } \\
\text { Gluconate } \\
\text { 2-KetoGlu- }\end{array}$ & - \\
\hline 10 & D-Galactose & - & 23 & Amygdalin & + & 36 & Amidon & - & & conate & \\
\hline 11 & D-Glucose & + & 24 & Arbutin & + & 37 & Glycogen & - & & Potassium & \\
\hline 12 & D-Fructose & + & 25 & $\begin{array}{l}\text { Esculin ferric } \\
\text { citrate }\end{array}$ & + & 38 & Xylitol & - & 49 & $\begin{array}{l}\text { Gluconate } \\
\text { 5-KetoGlu- } \\
\text { conate }\end{array}$ & - \\
\hline
\end{tabular}

\subsection{Khả năng ức chế vi sinh vật của chế phẩm PLA}

Khả năng kháng khuẩn của chế phẩm PLA

Với thử nghiệm PLA nguyên chất, kết quả cho thấy 4/4 chủng vi khuẩn khảo sát bị ức chế hoàn toàn (Bảng 6). Điều này có thể được giải thích bởi khả năng khuếch tán khá mạnh của PLA trên bề mặt thạch và với đặc tính acid nồng độ cao $(100 \%)$ đã làm ức chế hoàn toàn sự phát triển của các vi khuẩn khảo sát. Với nồng độ PLA thấp hơn $(5-30 \%)$ khả năng ức chế sự phát triển của các chủng vi khuẩn Escherichia coli, Salmonella, Staphylococcus aureus giảm rõ rệt. Đặc biệt chủng Shigela flexneri phát triển bình thường tại những giếng có nồng độ PLA 5 - 30\% (không hình thành vòng kháng).

Kết quả nghiên cứu khá tương đồng với một số báo cáo về hoạt tính kháng khuẩn của PLA. Ohhira và cộng sự cho rằng PLA có khả năng ức chế vi khuẩn E. coli, Samonella enterica với đường kính vòng kháng khuẩn 3 mm ở nông độ PLA 50 mM (15\%) [4].

\subsubsection{Khả năng kháng nấm của chế phẩm PLA}

Đánh giá khả năng kháng nấm của chế phẩm PLA được thực hiện trên 03 loại nấm: Aspergillus niger, Aspergillus oryzae và Aspergillus flavus. Kết quả ở Bảng 6 cho thấy PLA có khả năng kháng cả 03 loại nấm này. Với nông độ PLA 100\%, vòng ức chế có kích thước lớn nhất $(61,5$ $\mathrm{mm}$ ) đối với $A$. niger và thấp nhất $(40,6 \mathrm{~mm})$ với $A$. oryzae. Ở nông độ PLA $30 \%$ cũng có khả năng ức chế cao đối với sự phát triển của cả 03 chủng nấm này (vòng ức chế khá lớn 30,7 - 38,2 mm).

Bảng 6. Khả năng kháng khuân và nấm của PLA

\begin{tabular}{|c|c|c|c|c|c|c|c|}
\hline \multirow{2}{*}{$\begin{array}{c}\text { Nồng } \\
\text { dộ } \\
P L A \\
(\%)\end{array}$} & \multicolumn{7}{|c|}{ Đường kính vòng ức chế trung bình (D-d, mm) } \\
\hline & $\begin{array}{c}\text { Shigela } \\
\text { flexneri S1 }\end{array}$ & $\begin{array}{l}\text { Salmonella } \\
\text { enterica ST }\end{array}$ & $\begin{array}{l}\text { Escherichia } \\
\quad \text { coli } T 1\end{array}$ & $\begin{array}{l}\text { Staphylococcus } \\
\text { aureus SA }\end{array}$ & $\begin{array}{l}\text { Aspergillus } \\
\text { niger LN02 }\end{array}$ & $\begin{array}{c}\text { Aspergillus } \\
\text { oryzae A4 }\end{array}$ & $\begin{array}{l}\text { Aspergillus } \\
\text { flavus KN }\end{array}$ \\
\hline 0 & $0,0 \pm 0,0$ & $0,0 \pm 0,0$ & $0,0 \pm 0,0$ & $0,0 \pm 0,0$ & $0,0 \pm 0,0$ & $0,0 \pm 0,0$ & $0,0 \pm 0,0$ \\
\hline 5 & $0,0 \pm 0,0$ & $0,0 \pm 0,0$ & $0,0 \pm 0,0$ & $0,0 \pm 0,0$ & $0,0 \pm 0,0$ & $0,0 \pm 0,0$ & $0,0 \pm 0,0$ \\
\hline 15 & $0,0 \pm 0,0$ & $5,3 \pm 0,1$ & $7,3 \pm 0,02$ & $5,2 \pm 0,08$ & $10,5 \pm 0,2$ & $6,8 \pm 0,01$ & $6,0 \pm 0,01$ \\
\hline 30 & $0,0 \pm 0,0$ & $8,4 \pm 0,2$ & $11,6 \pm 0,1$ & $6,8 \pm 0,1$ & $38,2 \pm 0,3$ & $32,3 \pm 0,2$ & $30,7 \pm 0,6$ \\
\hline 100 & $42,2 \pm 0,8$ & $48,3 \pm 0,7$ & $50,1 \pm 0,8$ & $30,7 \pm 0,5$ & $61,5 \pm 0,6$ & $40,6 \pm 0,7$ & $53,8 \pm 0,5$ \\
\hline
\end{tabular}




\subsubsection{Xác định khả năng ức chế tối thiểu (MIC) của chế phẩm PLA}

Giá trị nồng độ tối thiểu ức chế sự phát triển của vi khuẩn và nấm khác nhau rõ rệt (Bảng 7). Với vi khuẩn, giá trị MIC thấp hơn $(20-30 \mathrm{mg} / \mathrm{mL})$ so với các chủng nấm khảo sát (40 - 50 $\mathrm{mg} / \mathrm{mL})$. Vi khuẩn $E$. coli bị ức chế hoàn toàn với nồng độ PLA $30 \mathrm{mg} / \mathrm{mL}$ cũng tương tự như báo cáo của Magnusson và cộng sự [9].

Bảng 7. Giá trị MIC của PLA với vi khuân và nấm

\begin{tabular}{cccccccc}
\hline Tên chủng & $\begin{array}{c}\text { Shigela } \\
\text { flexneri } \\
\text { S1 }\end{array}$ & $\begin{array}{c}\text { Salmonella } \\
\text { enterica ST }\end{array}$ & $\begin{array}{c}\text { Escherichia } \\
\text { coli T1 }\end{array}$ & $\begin{array}{c}\text { Staphylococcus } \\
\text { aureus SA }\end{array}$ & $\begin{array}{c}\text { Aspergillus } \\
\text { niger LN02 }\end{array}$ & $\begin{array}{c}\text { Aspergillus } \\
\text { oryzae A4 }\end{array}$ & $\begin{array}{c}\text { Aspergillus } \\
\text { flavus KN }\end{array}$ \\
\hline $\begin{array}{c}\text { Giá trị MIC } \\
(\mathrm{mg} / \mathrm{mL})\end{array}$ & 20 & 25 & 30 & 20 & 45 & 40 & 50 \\
\hline
\end{tabular}

\section{3. Ứng dụng của PLA trong bảo quản xoài và ớt}

\subsection{1. Úng dụng của PLA trong bảo quản xoài}

Chất lượng cảm quan của xoài được xác định theo phương pháp cho điểm thị hiếu dựa trên 03 chỉ tiêu: màu sắc, mùi vị, hình thức bên ngoài. Kết quả đánh giá cảm quan ở các thời điểm bảo quản cho thấy các mẫu xoài ở các công thức được đánh giá khác nhau về chất lượng cảm quan (Bảng 8). Xoài ở công thức đối chứng có điểm cảm quan về cả 03 chỉ tiêu kém nhất, thể hiện là điểm thị hiếu trung bình về màu sắc, mùi vị và hình thức đều dưới 4 điểm sau 28 ngày bảo quản. Ngược lại, xoài ở công thức 2 (xử lý $\mathrm{CaCl}_{2}$ và PLA) được đánh giá tương đối cao sau 28 ngày bảo quản với điểm trung bình từ 5,9 - 7,0 điểm.

Màu sắc có vai trò quan trọng trong các giá trị cảm quan của các sản phẩm củ quả. Chính màu sắc là một trong những yếu tố vô cùng quan trọng tác động đến người tiêu dùng khi lựa chọn sản phẩm. Hiển nhiên, màu sắc càng tươi, tự nhiên, thì sẽ càng hấp dẫn người tiêu dùng. Tuy nhiên, trong quá trình bảo quản có nhiều yếu tố tác động đến sản phẩm như nhiệt độ, độ ẩm, vi sinh vật,... làm màu sắc bị biến đổi.

Bảng 8. Chất lượng cảm quan của xoài và ớt

\begin{tabular}{cccccc}
\hline \multirow{2}{*}{ Chỉ tiêu } & \multirow{2}{*}{$\begin{array}{c}\text { Thòi gian bảo } \\
\text { quản }(\text { ngày) }\end{array}$} & \multicolumn{3}{c}{ Xoài } & \multicolumn{3}{c}{ Ốt cảm quan trung bình } \\
\cline { 3 - 6 } & & CT1 & CT2 & CT1 & CT2 \\
\cline { 3 - 6 } & 0 & $8,5 \pm 0,34$ & $8,5 \pm 0,26$ & $8,8 \pm 0,28$ & $8,8 \pm 0,31$ \\
Màu sắc & 14 & $6,2 \pm 0,26$ & $7,8 \pm 0,22$ & $4,5 \pm 0,15$ & $8,2 \pm 0,27$ \\
& 28 & $3,1 \pm 0,11$ & $5,9 \pm 0,17$ & $2,1 \pm 0,08$ & $7,6 \pm 0,26$ \\
\cline { 2 - 6 } Mùi, $\boldsymbol{v i ̣}$ & 0 & $8,8 \pm 0,35$ & $8,8 \pm 0,25$ & $8,3 \pm 0,26$ & $8,3 \pm 0,29$ \\
& 14 & $5,5 \pm 0,21$ & $7,9 \pm 0,23$ & $3,5 \pm 0,12$ & $7,9 \pm 0,28$ \\
& 28 & $2,1 \pm 0,07$ & $6,7 \pm 0,21$ & $2,0 \pm 0,06$ & $7,2 \pm 0,23$ \\
\cline { 2 - 6 } Trạng thái & 0 & $8,6 \pm 0,32$ & $8,6 \pm 0,25$ & $8,9 \pm 0,27$ & $8,9 \pm 0,30$ \\
& 14 & $6,5 \pm 0,25$ & $7,9 \pm 0,25$ & $4,5 \pm 0,13$ & $8,1 \pm 0,29$ \\
& 28 & $2,8 \pm 0,12$ & $7,0 \pm 0,22$ & $2,2 \pm 0,08$ & $7,0 \pm 0,24$ \\
\hline
\end{tabular}


Quan sát sự biến đổi màu sắc của xoài ở các công thức nhận thấy (Hình $3 \mathrm{~A}, \mathrm{~B}$ ) xoài ở công thức xử lý với PLA không bị biến đổi màu sắc nhiều ( $\Delta \mathrm{E}$ giảm từ 8,5 đến 5,9 sau 28 ngày), quả có màu vàng, vỏ quả hơi héo nhửng không xuất hiện các đốm đen, vỏ quả không nhây, trong khi màu sắc của xoài ở công thức không xử lý thay đổi nhiều hơn ( $\Delta \mathrm{E}$ giảm từ 8,5 đến 3,1 ), vỏ quả vàng đậm hơn, héo và xuất hiện nhiêu đốm đen, nhây và chảy nước. Như vậy, bảo quản xoài bằng PLA $2 \%$ kết hợp với $\mathrm{CaCl}_{2} 1 \%$ làm tăng thời gian bảo quản xoài lên 14 ngày so với không sử dụng chất bảo quản ở nhiệt độ $40^{\circ} \mathrm{C}$.
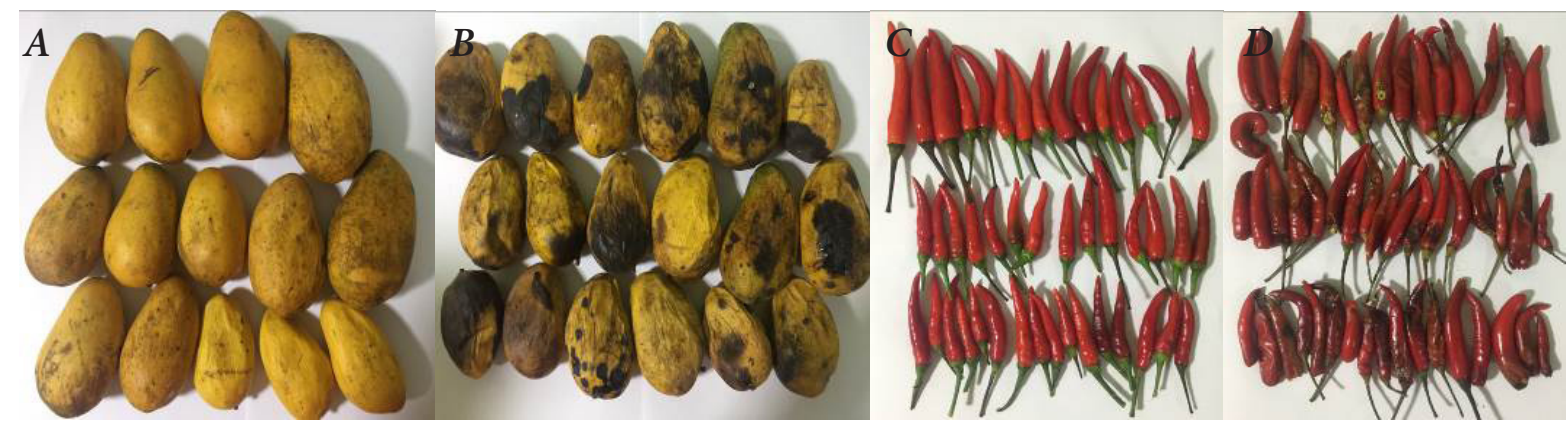

Hình 3. Sụ biến đổi của quả xoài và ớt theo các công thức thí nghiệm sau 28 ngày

$$
\text { A, C: CT2 (PLA 2\% } \left.+\mathrm{CaCl}_{2} 1 \%\right) ; \mathrm{B}, \mathrm{D}: \mathrm{CT1}
$$

Kết quả thu được này tương đương với những kết quả nghiên cứu của Mitra và cộng sự [8] công bố (dùng hypobaric và nhiệt độ thấp bảo quản xoài chín trong $2-4$ tuân) và ngắn hơn 10 ngày so với kết quả nghiên cứu của Lalel và Singh [15]. (xoài giữ được 38 ngày khi bảo quản trong $\mathrm{CO}_{2} 6 \%$ và $\mathrm{O}_{2} 3 \%$ ).

\subsection{2. Úng dụng của PLA trong bảo quản ớt}

Ớt được đánh giá là có màu sắc ban đầu rất đẹp mắt (8,8 điểm). Tuy nhiên, việc giảm về điểm cảm quan ở các công thức xử lý khác nhau rõ rệt. Điểm đánh giá này giảm xuống đáng kể từ 4,5 - 2,1 sau 14 và 28 ngày nếu không được xử lý với PLA (Bảng 8). Sau 28 ngày bảo quản, điểm cảm quan về màu sắc của công thức đối chứng là thấp nhất 2,1 điểm, trong khi điểm cao hơn thuộc về công thức 2 là 7,6 điểm. Hình 3 cũng cho thấy quả ớt khi bảo quản bằng PLA có màu đỏ tươi, quả bóng, chỉ có cuống bị héo trong khi ớt đối chứng (không xử lý PLA) bị héo, biến đổi màu sắc và có các đốm nhây trên bề mặt quả.

Tương tự, điểm cảm quan về mùi vị giảm từ 8,3 điểm (ban đầu) xuống 2,0 điểm sau 28 ngày (với công thức đối chứng) trong khi mùi vị của ớt được cho điểm rất cao đối với công thức xử lý PLA $2 \%$ kết hợp với $\mathrm{CaCl}_{2}$. Kết quả đánh giá cảm quan về trạng thái ở công thức đối chứng cũng thay đổi nhiêu theo thời gian bảo quản. Điểm cảm quan giảm đi đáng kể từ 8,3 - 8,9 xuống 3,5 - 4,5 sau 14 ngày và giảm tiếp xuống 2,0 - 2,2 sau 28 ngày. Điểm cảm quan của các công thức 2 cũng giảm xuống nhửng giảm ít (từ 8,9 đến 7,0 ). Nhìn chung, chất lượng cảm quan ớt của công thức xử lý PLA cao hơn nhiều so với đối chứng.

Kết quả nghiên cứu cho thấy quả ớt khi bảo quản ở điều kiện $4^{\circ} \mathrm{C}$ (không sử dụng chất bảo quản) chỉ giữ được 02 tuân, tương tự như báo cáo của Rico và cộng sự [16], Hameed và cộng sự [18]. Khi sử dụng chất bảo quản sinh học, thời gian bảo quản tăng lên 14 ngày so với đối chứng ở điều kiện nhiệt độ $4^{\circ} \mathrm{C}$. 


\section{KẾT LUẠN}

Nghiên cứu đã phân lập và tuyển chọn được chủng Lactobacillus sp. MX3.2 có khả năng sinh tổng hợp acid phenyllactic $1,98 \mathrm{~g} / \mathrm{L}$ từ 43 mẫu rau củ muối chua. Chế phẩm acid phenyllactic có khả năng ức chế hoàn toàn cả 03 loài nấm mốc là Aspergillus niger, Aspergillus flavus và Aspergillus oryzae ở nông độ $40-50 \mathrm{~g} / \mathrm{L}$ và 03 loài vi khuẩn gây hại là E. coli, Salmonella enterica và Shigela flexneri ở nông độ 20 - $30 \mathrm{~g} / \mathrm{L}$. Quả xoài và ớt khi sử dụng PLA ở nông độ $2 \%$ kết hợp với $\mathrm{CaCl}_{2} 1 \%$ trong 2 phút để bảo quản cho thấy sản phâm đảm bảo chất lượng lên tới 28 ngày, kéo dài hơn so với không xử lý 14 ngày.

\section{TÀI LIẸU THAM KHẢO}

[1]. Võ Thị Phương Nhung, Đỗ Thị Thúy Hằng và Võ Thị Hải Hiền, "Xuất khẩu rau quả Việt Nam - thực trạng và giải pháp," Tạp chí Khoa học và Công nghệ Lâm Nghiệp, số 20/10/2017, tr. 160-168, 2017.

[2]. S. S. Chaudhari and D.V. Gokhale, "Phenyllactic acid: A potential antimicrobial compound in lactic acid bacteria," Journal of Bacteriology and Mycology: Open Access, vol. 2, no. 5, pp. 121-125, 2016.

[3]. P. Lavermicocca, F. Valerio, and A. Visconti, "Antifungal activity of phenyllactic acid against molds isolated from bakery products," Applied and Environmental Microbiology, vol. 69, no. 1, pp. 634-640, 2003.

[4]. I. Ohhiral, S. Kuwaki, H. Morita, T. Suzuki, S. Tomita, S. Hisamatsu, S. Sonoki and S. Shinoda, "Identification of 3-Phenyllactic acid as a possible antibacterial substance produced by Enterococcus faecalis TH 10," Biocontrol Science, vol. 9, no. 3, pp. 77-81, 2004.

[5]. Bùi Kim Thuý và Nguyễn Duy Lâm, "Nghiên cứu sản xuất axít phenyllactic bằng phương pháp lên men và ứng dụng trong bảo quản dứa cắt và cam," Tạp chí Khoa học và Công nghệ, Tập 51, số 6A, tr. 283-288, 2013.

[6]. Nguyễn Thị Minh Hằng và Nguyễn Minh Thư, "Phân lập và tuyển chọn một số chủng vi khuẩn Lactic có khả năng sinh tổng hợp amylase và bacteriocin,” Tạp chí Khoa học và Công nghệ Lâm nghiệp, tập 3, số 1, tr. 3-10, 2013.

[7]. M. V. Arasu, M. W. Jung, S. Ilavenil, M. Jane, D-H. Kim, K-D. Lee, H-S. Park, T-Y. Hur, G-J. Choi, Y-C. Lim, N. A. Al-Dhabi, and K-C. Choi, "Isolation and characterization of antifungal compound from Lactobacillus plantarum KCC-10 from forage silage with potential beneficial properties," Journal of Applied Microbiology, vol. 115, no. 5, pp. 11721185, 2013.

[8]. J. Magnusson and J. Schnurer, "Lactobacillus coryniformis subsp. coryniformis strain Si3 produces a broad-spectrum proteinaceous antifungal compound," Applied and Environmental Microbiology, vol. 67, no.1, pp. 1-5, 2001.

[9]. J. Magnusson, K. Strom, S. Roos, J. Sjogren, and J. Schnurer, "Broad and complex antifungal activity among environmental isolates of lactic acid bacteria," Fems Microbiology Letters, vol. 219, no. 1, pp. 129-135, 2003.

[10]. J. A. Yoo, Y. M. Lim, and M. H. Yoon, "Production and antifungal effect of 3-phenyllactic acid (PLA) by lactic acid bacteria," Journal of Applied Biological Chemistry, vol. 59, no. 3, pp. 173-178, 2016.

[11]. W. Mu, S. Yu, L. Zhu, T. Zhang, and B. Jiang, "Recent research on 3-phenyllactic acid, a 
broad-spectrum antimicrobial compound," Applied Microbiology and Biotechnology, vol. 95, no. 5, pp. 1155-1163, 2012.

[12]. D. S. Joshi, M. S. Singhvi, J. M. Khire, and D. V. Gokhale, "Strain improvement of Lactobacillus lactis NCIM 2368 for D-lactic acid production," Biotechnology Letters, vol. 32, no. 4, pp. 517-520, 2010.

[13]. Huỳnh Ngọc Tâm, Trần Thanh Trúc, Nguyễn Văn Mười và Hà Thanh Toàn, "Phân lập và tuyển chọn dòng vi khuẩn lactic có khả năng kháng khuẩn từ dưa lê non (Cucumis melo L.) muối chua, Tạp chí Khoa học Truiơng Đai học Cần Thơ, tập 1, tr. 18-24, 2016.

[14]. X. F. Li, B. Jiang, and B. Pan, "Biotransformation of phenylpyruvic acid to phenyllactic acid by growing and resting cells of a Lactobacillus sp." Biotechnology Letters, vol. 29, no. 4, pp. 593-597, 2007.

[15]. M. Kamata, R. Toyomasu, D. Suzuki, and T. Tanaka, "D-phenylactic acid production by Brevibacterium or Corynebacterium," Patent JP, 86108396, 1986.

[16]. H. J. D. Lalel and Z. Singh, "Controlled atmosphere storage of "Delta R2E2" mangoes fruit affects production of aroma volatile compounds," The Journal of Horticultural Science and Biotechnology, vol. 81, no. 3, pp. 449-457, 2006.

[17]. D. Rico, A. B. Martin-Diana, J. M. Barat, and C. Barry-Ryan, "Extending and measuring the quality of fresh cut fruits and vegetables: A review," Trends in Food Science and Technology, vol.18, no. 7, pp. 373-386, 2002.

[18]. S. Mitera, E. A. Baldwin, and Mango In, Post harvest physiology and storage of tropical and sub tropical fruit, S. Mitra, CABI, West Bangal: India, 2005.

\title{
Collection of phenyllactic acid from a strain of Lactobacillus $\mathbf{~ s p . ~}$ and application in agricultural products preservation
}

\author{
Dung Vu Kim, Nhu Ngoc Nguyen, Sy Dung Le, Ngoc Hien Vu Thi \\ Vietnam National University of Forestry, Hanoi, Vietnam
}

\section{Abstract}

Phenyllactic acid (PLA) is a biological compound from microorganisms. PLA is capable of inhibiting the growth and development of some pathogen organisms such as gram-negative, gram-positive, yeast-like, and mold. This paper shows the results of studying the isolation and selection of Lactobacillus sp. MX3.2, which is capable of producing a high amount of phenyllactic acid $(1.98 \mathrm{~g} / \mathrm{L})$ from sour vegetables. The PLA obtained from fermentation broth of Lactobacillus sp. MX3.2 has been tested to some strains like Aspergillus niger, Aspergillus flavus, and Aspergillus oryzae at concentrations of $40-50 \mathrm{~g} / \mathrm{L}$, and E. coli, Salmonella enterica, and Shigela flexneri at concentrations of $20-30 \mathrm{~g} / \mathrm{L}$. The results showed that almost all these strains were inhibited. Besides, the obtained PLA also showed high effectiveness in protecting some agricultural products from pathogens. Mango and chilli, which were treated with 2\% PLA and $\mathrm{CaCl}_{2} 1 \%$ for two minutes after 28 days of storage, retained freshness, tastiness, and good sensory quality longer than 14 days without treatment.

Keywords: Lactobacillus, phenyllactic acid, protect, selection. 